\title{
Aula de história: subjetividade e memória na aprendizagem de alunos
}

\author{
Beatriz Judith Lima Scoz \\ Centro Universitário FIEO/UNIFIEO - SP \\ Vilma Nardes Silva Rodrigues \\ Centro Universitário FIEO/UNIFIEO - SP
}

\begin{abstract}
Resumo
Este artigo apresenta o relato de uma pesquisa sobre as relações entre memória individual e memória coletiva nas aulas de História para compreender suas interferências na produção de sentidos subjetivos dos alunos na aprendizagem de História. A coleta de dados foi feita a partir do filme "Narradores de Javé" e da "conversação livre" com alunos da $8^{a}$ série de uma escola pública de São Paulo. A pesquisa fundamenta-se nas concepções teóricas de Halbwachs e Placco, \& Souza acerca da memória. No que tange à questão da subjetividade, o autor privilegiado é Fernando González Rey. Os resultados da pesquisa apontam complexa implicação subjetiva entre a história da humanidade e as histórias individuais. A memória apresentou-se como facilitadora da produção de sentidos subjetivos dos alunos em seus processos de aprendizagem de História, possibilitando uma aproximação para compreender a construção de suas subjetividades nesses processos.
\end{abstract}

Palavras-chave: História; subjetividade; memória.

\section{History Class: subjectivity and memory in students learning}

\begin{abstract}
This article presents a research report on the relationships between individual memory and collective memory in history classes. Our intention is to understand the interference in the production of subjective senses of students in learning history. The data collected was based on the film "Narradores de Javé" followed by "free conversation" with students of the 8th grade of a public school in São Paulo. The research is based on the theoretical conceptions of Halbwachs (2004) and Placco\& Souza, (2006) about the memory. With regard to the question of subjectivity, the main author is Fernando González Rey $(2003,2012)$. The survey results point to the complex subjective implication between the history of mankind and the individual stories. Memory performed as a facilitator of subjective senses of the students in their learning processes of History, allowing an approach which helped to understand the construction of their subjectivities in these processes.
\end{abstract}

Key-words: History; subjectivity; memory

\section{Clase de Historia: subjetividad y memoria en el aprendizaje de alumnos}

\section{Resumen}

Este artículo presenta el relato de una investigación sobre las relaciones entre memoria individual y memoria colectiva en las clases de Historia para comprender sus interferencias en la producción de sentidos subjetivos de los alumnos en el aprendizaje de Historia. La recolecta de datos se realizó a partir de la película "Narradores de Javé" y de la "charla libre" con alumnos del 8 curso de una escuela pública de São Paulo. La investigación se fundamenta en las concepciones teóricas de Halbwachs y Placco \& Souza acerca de la memoria. En lo que tañe a la cuestión de la subjetividad, el autor elegido es Fernando González Rey. Los resultados de la investigación apuntan complexa implicación subjetiva entre la historia de la humanidad y las historias individuales. La memoria se presentó como facilitadora de la producción de sentidos subjetivos de los alumnos en sus procesos de aprendizaje de Historia, posibilitando un acercamiento para comprender la construcción de sus subjetividades en esos procesos.

Palabras-clave: Historia; subjetividad; memoria. 


\section{Introdução}

Os estudos nas aulas de História passam pela necessidade da compreender aspectos da subjetividade do sujeito construída na individualidade e no contexto social. O sujeito está inserido em espaços sociais e os sentidos subjetivos individuais produzidos por ele nesses espaços sofrem interferências de outros sentidos produzidos coletivamente na realidade concreta do cotidiano. Nesse processo de compreensão da subjetividade é necessário considerar ainda a influência do espaço e do tempo. Nessa complexa e dinâmica trama, sentidos singulares e coletivos se confrontam, convergem e implicam a recíproca constituição do próprio sujeito, de sua subjetividade e do meio histórico-cultural. Assim, os fatos históricos são construídos por sujeitos que, ao construí-los, também se constroem no processo histórico.

Não obstante, nas aulas de História percebe-se com frequência que o conhecimento é compreendido como algo exterior ao aluno e que este precisa compartimentar os saberes produzidos por outros. Esta situação acarreta problemas: quando os alunos têm que "engavetar" conceitos pré-construídos e não conseguem conectá-los à realidade para compreendê-los, muitas vezes são considerados maus alunos, e quando questionam tal metodologia, são percebidos como indisciplinados e/ou "quebradores" de acordos firmados unilateralmente pelo professor e pela escola. A História, se compreendida como unidade desconexa do sujeito e da totalidade, pode contribuir para uma visão fragmentada do conhecimento e interferir nas produções de sentidos subjetivos dos alunos nos processos de aprendizagem da própria História.

Também é comum o estudo da História ater-se a apenas alguns fatos marcantes presentes na memória coletiva da humanidade, que os alunos frequentemente reproduzem de forma mecânica - portanto, sem reflexão. Desse modo, os alunos não são considerados como seres portadores de uma historicidade carregada de memórias coletivas e individuais, o que afeta suas produções de sentidos subjetivos na aprendizagem da História.

Diante de tal situação, a pesquisa relatada neste artigo teve por objetivo investigar as relações entre as memórias coletivas e as memórias individuais na aula de História e suas implicações nas produções de sentidos subjetivos dos alunos nos processos de aprendizagem de História.

\section{A subjetividade nos processos de aprender e de ensinar}

A subjetividade vem sendo discutida com muita ênfase nas últimas décadas, quando se percebeu que diversas situações humanas podem ser compreendidas quando analisadas a partir da subjetividade, porém algumas pesquisas têm demonstrado que a natureza complexa do sujeito e da subjetividade tem sido pouco considerada na educação (Scoz, Castanho, \& Tacca, 2010, 2012). De fato, algumas análises sobre formação de professores, continu- ada ou em serviço (Gatti, 2003), que vise a mudanças em cognições e práticas, têm demonstrado um fato preciso: em geral, os mentores e implementadores desses cursos de formação têm a concepção de que, oferecendo informações e conteúdos ou trabalhando apenas a racionalidade dos profissionais, produzirão, a partir do domínio de novos conhecimentos, mudanças em suas posturas e formas de agir. Essa concepção, essencialmente intelectual, não dá conta de perceber que os professores são indivíduos com subjetividades, são sujeitos que vão produzindo sentidos em seus processos de aprender e de ensinar, nos quais se integram suas condições sociais e afetivas, seus pensamentos e suas emoções. Isto pode ser uma das razões pelas quais tantos programas que buscam mudanças cognitivas, de práticas e de posturas, mostram-se ineficazes, causando, além disso, desperdício de tempo e dinheiro. De fato, análises dos resultados de alguns programas de formação de professores (Placco, \& Silva 2000) apontam que são poucos os aspectos trabalhados que têm se traduzido em ações diferenciadas ou transformadoras em sala de aula.

Talvez por detrás dessas concepções esteja presente a dificuldade do sistema educativo em reconhecer, tratar e pensar a complexidade do ser/existir humano. Um exemplo disso é a fragmentação das disciplinas e delas em si mesmas, quebrando a sistemicidade (a relação de uma parte com o todo), a multidimensionalidade e a temporalidade dos fenômenos. Desse modo, isolando e/ou fragmentando seus objetos, esse mundo de conhecimento acaba por eliminar não somente seu contexto, mas, também sua singularidade, sua localidade, seu ser, sua existência. É o que se percebe nas aulas de História, objeto deste estudo.

\section{História, sujeito e subjetividade}

A história da humanidade, segundo a concepção histórico-cultural, é construída por sujeitos que, ao construí-la, também se constroem no processo histórico. Afirma González Rey, 2003 (p. 9):

As criações humanas são produtoras de sentido que expressam de forma singular complexos processos da realidade. Esses processos são criações humanas que integram diferentes aspectos do mundo em que o sujeito vive, aparecendo em cada sujeito ou espaço social de forma única, organizados em seu caráter subjetivo pela história de seus protagonistas.

Para a compreensão da integração contida no conceito de "sentido subjetivo" González Rey (2005) toma um conceito de "configuração de sentidos" a partir do qual ele ressalta a capacidade de unir diversos sentidos de forma flexível e processual. Em uma mesma configuração aparecem elementos de diferentes sentidos e gerados em tempos e espaços diferentes da vida do sujeito.

O sujeito, por meio da produção de sentidos subjetivos em sua trajetória de vida, constrói-se como sujeito 
singular e se atualiza, reconstruindo-se permanentemente. Pode-se afirmar então que esse sujeito se faz e se refaz numa recursividade em que se move e, ao mesmo tempo, está clivado pelo outro com quem convive e pelo contexto histórico em que está inserido. Afirma ainda González Rey:

O sujeito representa um momento de subjetivação dentro dos espaços sociais em que atua e, simultaneamente, é constituído dentro desses espaços na própria processualidade que caracteriza sua ação dentro deles, a qual está sempre comprometida direta ou indiretamente com inúmeros sistemas de relação (González Rey, 2003, p. 235).

Nessa perspectiva, o sujeito é afetado pelo meio histórico-social no qual atua; e entre o individual e o social, o sujeito se faz, produz sentidos e significa seu viver.

González Rey (2003) afirma ainda que o sentido representa um sistema subjetivo que expressa de forma singular uma experiência vivenciada pelo sujeito. Esse sentido singular, por sua vez, é permeado pelas subjetivações do espaço social onde o sujeito está inserido. Por isso a categoria "sentido subjetivo" faz parte da qualidade do psíquico e, ao mesmo tempo, rompe a dicotomia individual-social, favorecendo uma representação da subjetividade que permite entender que a constituição do sujeito é produzida em ambas as condições histórica e culturalmente influenciada.

1. O circuito recursivo ou autoprodutivo rompe com a causalidade linear; ou seja, nós mesmos somos os efeitos e os produtos de um processo de reprodução. (Morin, 1997).

\section{Explica González Rey que}

[...] a subjetividade não se internaliza, não é algo que vem de "fora" e que aparece "dentro", o que seria uma forma de manter a dualidade em outros termos. Em minha opinião, trata-se de compreender que a subjetividade não é algo que aparece somente no nível individual, mas que a própria cultura dentro da qual se constitui o sujeito individual, e da qual é também constituinte, representa um sistema subjetivo, gerador de subjetividade (González Rey, 2003, p. 78).

Neste sentido, a subjetividade não é simplesmente a apropriação do externo pelo interno, mas constitui-se diante de um processo em que o plano histórico-cultural atua como instância subjetiva. González Rey (2003) defende que o plano histórico-cultural é uma instância perpassada pela subjetividade e que toda situação social objetiva se expressa com sentidos subjetivos.

Segundo González Rey (2003), essa concepção da organização subjetiva do plano histórico-cultural, que permite superar a dicotomia do social e do individual, demonstra que nenhuma influência social concreta ou comportamento pontual do sujeito podem ser analisados isoladamente como um determinante gerado fora da condição subjetiva do próprio sujeito, pois nesta se sintetizam os sentidos de suas múltiplas experiências sociais ao largo de sua história individual.

A abordagem histórico-cultural acerca da subjetividade pode ser explicitada do seguinte modo nos processos de aprendizagem. Esclarece o mesmo autor (pp. 196-197):

[...] o aprendizado, que até hoje constitui um campo particular de produção do conhecimento psicológico, se converteria em um campo que integraria o estudo da constituição subjetiva do sujeito que aprende, pois dela dependerá, entre outros elementos, a produção de sentidos no processo de aprendizado. Nessa perspectiva, o aprendizado estaria mediatizado pelos sentidos subjetivos manifestados em outras esferas da vida do sujeito.

Considerando-se as questões anteriormente citadas, o ensino de História precisa ir além da transmissão de conteúdos, inserindo-se a compreensão da produção subjetiva dos alunos nos processos de aprendizagem dessa disciplina. Também é importante que os alunos percebam, eles mesmos, suas produções de sentido, considerando as relações entre as memórias coletivas e individuais. Sem isso, fica difícil para os alunos a percepção de suas inserções no processo histórico da humanidade e também a compreensão de conceitos nas aulas de História.

\section{História e memória}

O recurso da memória relacionado às histórias de vida é defendido por Halbwachs (2004). Afirma o autor:

\begin{abstract}
Os quadros coletivos da memória não se resumem a datas, nomes e fórmulas; eles representam correntes de pensamento e de experiências onde reencontramos nosso passado porque este foi atravessado por tudo isso [...] a memória apoia-se sobre o "passado vivido", o qual permite a constituição narrativa do passado do sujeito de forma viva e natural [...] ( Halbwachs, 2004, p. 71-75).
\end{abstract}

A memória, porém, não é um depósito de tudo o que acontece. Ela é, por excelência, seletiva. Guarda-se aquilo que, por algum motivo, teve ou tem algum significado, aquilo sobre o qual o sujeito produz sentido. Explicam Placco e Souza (2006, p. 26):

A memória é o ponto de partida e chegada; ela nos enche de sentido. Recriamos o legado de gerações e de tantas contribuições significativas ao conhecimento humano, com os olhos e os filtros de hoje. Neste processo, contracenam o individual e o coletivo, o antigo diante do novo e, ao apropriar-se do que ainda é desconhecido, revelamos contrastes, semelhanças e diferenças. Portanto, a memória mistura tudo: sensações, emoções e lembranças. 
Assim, a história singular e a história coletiva representam uma organização dos sentidos subjetivos produzidos a partir de situações vividas e guardadas na memória. Por meio desta organização é possível rever e refazer caminhos já percorridos, consolidando a produção de sentidos subjetivos individuais e coletivos; ou seja, revisitar as próprias memórias faz com que os sujeitos repensem suas histórias, compreendam os sentidos subjetivos produzidos por outros sujeitos no passado e a produção de novos sentidos subjetivos no presente.

Placco e Souza (2006, p.25) afirmam ainda que "utilizar-se das experiências passadas, valer-se do que se sabe, trilhar caminhos conhecidos, ressignificando-os são algumas das dádivas da memória. A memória nos enriquece com seus conteúdos, empresta cor, profundidade e significado às nossas percepções".

A partir de tal afirmação, Placco e Souza (2006) enfatizam que a memória constitui matéria-prima para a possibilidade do processo de transformação. É possível alterar pontos de vista, construir novos olhares, fazer novas escolhas e abandonar ou confirmar certezas anteriores por intermédio de um movimento contínuo de desafios e enfrentamentos que lança o sujeito adiante - ou seja, a memória possibilita a produção de novos sentidos subjetivos.

Desse modo, consideramos que a memória, entrelaçada à subjetividade nos processos de aprendizagem de História, é relevante pela compreensão de que a aprendizagem é mediada pelos sentidos subjetivos manifestados em outras esferas da vida do sujeito, e que a produção de sentidos e significados são integrados a formas históricas e atuais de subjetivação produzidas em diferentes espaços sociais.

Nas aulas de História, a memória, ao refazer e recriar as experiências passadas entrelaçadas com a dimensão subjetiva do sujeito, pode ser explicitada e enriquecida com o auxílio não só de palavras, mas também de imagens, de ideias, etc., recursos que trazem a marca do movimento, do inacabado, da dimensão processual em direção ao futuro, provocando transformações e permanências.

\section{Método}

Nesta pesquisa foi utilizada a epistemologia qualitativa proposta por González Rey ( 2005). Em investigações que tratam da subjetividade o autor se posiciona em um de seus aspectos: a complexidade. Ele enfatiza que "(...) a complexidade expressa uma tensão constante entre organização e processo, entre continuidade e ruptura, que rompe com o determinismo mecanicista" (González Rey, 2005, p. 8).

Ao considerar a superação de um conhecimento em correspondência linear com a realidade, tendo-a como um processo de construção capaz de gerar campos de inteligibilidade que possibilitam o surgimento de novas zonas de sentido, González Rey (2005) defende o caráter construtivo-interpretativo do conhecimento na pesquisa, compreendendo-a como um processo de comunicação. Nesse sentido, "(...) o pesquisador converte-se em um núcleo gerador de pensamento que é parte integrante do curso da pesquisa" (González, Rey, 2005, p. 12). O instrumento de pesquisa não é considerado como fim, pois seu foco é desviado, facilitando a expressão do sujeito. Na pesquisa "(...) a pessoa conseguirá expressar-se em toda a sua complexidade se inserida em espaços capazes de implicá-la através da produção de sentidos subjetivos." (González Rey, 2003, p. 15).

O conhecimento como produção construtivo-interpretativa significa que, no mesmo momento em que os dados são levantados, emerge também o caráter interpretativo, que possibilita a produção de novos sentidos sobre o fenômeno estudado. Nessa perspectiva, a produção de conhecimento coloca a relação entre o pesquisador o participante da pesquisa e as relações dos participantes entre si como elementos centrais do processo de investigação. "Tanto os sujeitos pesquisados, como o pesquisador, integram suas experiências, suas emoções e suas tensões, em um processo que facilita o emergir de sentidos subjetivos." (González Rey, 2005, p. 46). Dessa forma, podemos avaliar que essa integração também pode desencadear inúmeras memórias que, por sua vez, favorecem a compreensão da produção de sentidos pelos próprios participantes da pesquisa e, consequentemente, uma aproximação de suas subjetividades em construção.

Por outro lado, o caráter construtivo-interpretativo das pesquisas destaca o lugar ativo do pesquisador, uma vez que a forma indireta e complexa em que aparecem os indicadores da subjetividade - por meio das diferentes formas de expressão do sujeito - só pode ser visualizada se estiver localizada dentro de espaços teóricos construídos hipoteticamente mediante processos de interpretação e construção do investigador.

Os instrumentos utilizados na pesquisa foram o filme "Narradores de Javé"1 , a conversação livre e a entrevista semidirigida a partir de trechos do filme. A conversação livre e a entrevista foram gravadas e transcritas para posterior análise descritiva e qualitativa.

A escolha de um filme como instrumento de pesquisa ocorreu porque, como afirma González Rei (2005, p. 79), "[...] esse recurso apresenta uma riqueza como modelo de vida real que facilita muito o envolvimento dos sujeitos estudados no nível do sentido subjetivo".

Nas pesquisas acerca da subjetividade, a busca pelo conhecimento converte-se na necessidade de criar espaços nos quais seja possível produzir entendimentos. Não basta a palavra declarada dos participantes da pesquisa, é necessário ir além, é necessário fazer uso de instrumentos de investigação que facilitem a busca e aprofundem a compreensão dos fenômenos investigados, no caso desta pesquisa, as relações entre as memórias individuais e coletivas e suas

\footnotetext{
1 O filme mostra o Vale do Javé, às margens do Rio São Francisco, no Brasil. Os moradores dessa região encontram-se na iminência de inundação de suas terras para a construção de uma barragem e sem nenhuma documentação formal que comprove que aquelas terras Ihes pertencem. Passam então a resgatar suas memórias evocando lembranças, buscando as origens de Javé. A diretora do filme, Eliane Caffé, tem formação em Psicologia e fez curso de cinema em Cuba e na Espanha.
} 
implicações para a compreensão dos sentidos subjetivos produzidos pelos alunos na aula de História.

Além disso, o filme "Narradores de Javé" aborda um tema atual e mostra a memória em sua dinâmica, e não como algo guardado em uma gaveta ou em uma "caixa secreta" que em algum momento possa ser resgatada. A memória é trabalho, é imaginação, como mostram os narradores de Javé. Ao mesmo tempo, a memória é lembrança e esquecimento; é trabalho de criação em função do presente que se relaciona com os sentidos subjetivos produzidos pelos sujeitos em suas trajetórias de vida.

Nas entrevistas semidirigidas com os alunos foram utilizadas as seguintes questões: 1- Quais foram suas lembranças a partir do filme?; 2- Qual a cena marcante do filme para você?; 3- O que você modificaria nessa cena (marcante)?; 4- Quais as relações entre o filme e os processos de aprendizagem de História?

Na coleta de dados participaram oito adolescentes na faixa etária de treze a catorze anos que cursavam o oitavo ano do Ensino Fundamental em uma escola pública estadual do município de Carapicuíba, Região Metropolitana de São Paulo/BR. A escolha desta escola deve-se ao fato de ser o local em que uma das pesquisadoras já atuava como professora de História havia dezenove anos e onde ela construíra um vínculo com os alunos. Tais características facilitaram um olhar mais claro para as especificidades dos alunos, na busca por entender os sentidos subjetivos produzidos em seus processos de aprendizagem.

A partir do interesse manifesto pelos participantes da pesquisa, estes receberam duas cópias do Termo de Consentimento Livre e Esclarecido (TCLE), por meio do qual o responsável autorizou a participação deles na pesquisa. Todos esses procedimentos ocorreram conforme as normas do Comitê de Ética em Pesquisa com Seres Humanos estabelecidas pela Resolução N. ${ }^{\circ} 196 / 96$ do Conselho Nacional de Saúde.

O início do encontro para a realização da pesquisa foi marcado pela ansiedade e pela expectativa, sensações que se evidenciavam no olhar, nos gestos e na linguagem dos alunos; mas após a explicação sobre a pesquisa, a projeção do filme, as discussões e as entrevistas, a tranquilidade dos alunos tornou-se visível.

A partir das gravações, fez-se uma ampla leitura do material obtido, tendo-se como referencial teórico-metodológico as concepções de González Rey acerca da subjetividade fundamentadas na abordagem histórico-cultural (2003). Como anteriormente mencionado, o autor enfatiza que nessa abordagem "[...] a subjetividade aparece como forma de organização da psique que tem no sentido subjetivo sua principal unidade constitutiva" (González Rey, 2003, p.252).

\section{Resultados e discussão}

Os dados da pesquisa indicam a relação entre a dimensão cognitiva e a dimensão afetiva no processo de reflexão, de aprendizagem e de aquisição do conhecimento sobre determinado fato histórico - apresentado no filme de forma relacionada com outros fatos históricos e com vivências pessoais. Assim, os dados permitem que se enfatize a produção de sentidos subjetivos e o processo de ressignificação e de configuração subjetiva a partir da temática apresentada no filme e nas discussões. Estas foram elaboradas pelos participantes da pesquisa na perspectiva construtivo-interpretativa proposta por González Rey.

\section{Conversação Livre}

A conversação livre a partir do filme induziu os alunos a se manifestarem de forma espontânea e prazerosa. Diferentemente do que ocorre em uma aula tradicional de História, todos tinham o que falar. As reflexões que os alunos faziam encontravam-se com as das pesquisadoras. Tanto os participantes da pesquisa quanto as pesquisadoras integravam suas experiências, o que facilitava emergir sentidos subjetivos no curso da conversação.

À medida que tanto os participantes da pesquisa quanto as pesquisadoras integravam suas experiências, facilitando a emergência de sentidos subjetivos no curso da conversação, evidenciava-se claramente a abordagem de González Rey (2005) sobre o caráter construtivo-interpretativo na pesquisa.

A conversação livre a partir do filme também instigou a reflexão, fazendo os alunos se perceberem como parte integrante da situação. Levou-os a pensar na história das pessoas e a ressignificar fatos históricos, e partindo daí, a refletir e a produzir novos sentidos a respeito de suas próprias histórias, evidenciando suas subjetividades em construção.

As falas dos alunos revelaram também suas percepções sobre o entrelaçamento de fatos históricos com suas histórias particulares. Mostraram como eles se enxergavam no processo de aprendizagem de História e quanto esta interferia em suas produções de sentidos, evidenciaram-se, assim, vínculos entre os sentidos singulares e os sentidos coletivos.

A importância da memória para a aprendizagem de História também foi percebida pelos alunos. Eles enxergaram as interferências mútuas do passado e do presente e, a partir daí, produziram novos sentidos em seus processos de aprender.

Nas seguintes falas percebem-se essas questões:

"Gostei do filme porque conta a história do Vale de Javé [...] a gente entra no filme. Fico pensando na minha vida, em nossa vida. Quantas pessoas passam pela mesma coisa”; " Ao assistir esse filme eu me vi dentro da História. O professor e o aluno entram dentro da História e eles têm que ficar bem próximos, tem que ter confiança senão, não se aprende".

E ainda:

"Eu acho que esse filme fez a gente pensar e aprender porque acontecem as coisas que a gente vê agora. Se não 
fossem as invenções antigas não haveria as de hoje e nem haverá as do futuro [...] é a mesma coisa que o povo de Javé, que também precisava pesquisar seu passado, a sua história".

\section{Entrevistas}

A partir da conversação livre foram apresentadas as quatro questões já mencionadas: a) "Quais foram suas lembranças a partir do filme?"; b) "Qual a cena marcante do filme para você?"; c) "O que você modificaria nessa cena (marcante)?"; d) "Quais as relações entre o filme e os processos de aprendizagem de História?".

\section{a) As lembranças a partir do filme}

Foram citadas diferentes lembranças pelos alunos entrevistados. Alguns referiram suas vivências, marcadas de forma positiva ou negativa. A memória era viva e aparecia em toda a sua intensidade nas recordações que eram resgatadas no presente para ressignificar o viver, como apontam os seguintes comentários:

"Meus pais são de Alagoas. Minha mãe conta que veio em busca de um sonho, mas o que ela queria mesmo era ficar em sua terra. Moramos em muitos lugares. Hoje não ficamos mais mudando. Por mais que falem mal, eu gosto daqui. $A$ gente precisa de um lugar". "Lembro de uma desapropriação de terra lá perto de casa. Tiraram muitas famílias de uma área. No filme de "Javé" foi igual. Tiraram as famílias para fazer uma barragem. Só que, em Carapicuíba, tiraram as famílias dizendo que era para fazer uma escola, mas até hoje não tem nada lá"”

\section{b) As cenas marcantes do filme}

Nos relatos dos alunos observou-se a convergência de sentidos subjetivos individuais e sociais na compreensão da História. Os alunos perceberam a importância que tinha para eles a aprendizagem da História. As seguintes falas remetem a essas questões:

"Para mim, a cena mais marcante foi aquela que cada morador conta uma história diferente. Achei legal a criatividade do povo. Me fez pensar que cada um de nós também tem a sua própria história. Por isso, dá tanta confusão na aula. Cada um se interessa por uma coisa". "O filme ajuda a aprender a História do Brasil, a propriedade da terra, neste país tão grande há muitas pessoas que não podem ter uma terra"; "Gostei muito do filme porque as pessoas são parte da História. O mais importante é também perceber que a História faz parte da história de cada um".

\section{c) As cenas marcantes modificadas}

Aspectos de permanência e mudança são contemplados nos relatos dos alunos. Revelam assim a complexidade do paradoxo de mudar ou permanecer, enfim a dimensão de processualidade e movimento das próprias subjetividades em construção. A evocação da memória induzida pelo filme também está presente nas falas dos alunos, contribuindo para a integração entre o presente, o passado e o futuro. As falas a seguir demonstram essas questões:

\begin{abstract}
"Não mudaria as cenas, porque elas mostram a realidade. Quem sabe a partir delas as pessoas pensariam e ajudariam mais o próximo. Como dizem: pensar no outro, colocar-se no lugar do outro. Pode ser no Nordeste ou na tragédia que ocorreu em Santa Catarina ${ }^{2}$ com o desmoronamento dos morros"; "Eu mudaria. Teria que ensinar as pessoas a ler e a escrever, assim elas poderiam perceber suas próprias histórias, contar dos seus jeitos a história das suas cidades e compreender melhor a história da humanidade".
\end{abstract}

\section{d) As relações entre o filme e os processos aprendizagem de História}

Na projeção do filme e a partir dela, os alunos revelaram em suas expressões (de alegria, silêncio, concentração) e em suas narrativas que é mais fácil e prazeroso lidar com a imagem como recurso para aprender História. Como disse um dos alunos: "A imagem vale mais, a gente vê a ideia nela". Além disso, a imagem, o movimento, a sonoridade e as narrativas, especialmente para o adolescente, são muito significativos.

"As imagens na pesquisa têm uma riqueza como modelo de vida real que facilita muito o envolvimento [...] cria uma atmosfera lúdica na qual se expressa uma total espontaneidade" (González Rey, 2005, p. 69).

As qualidades do filme mencionadas acima chegaram onde a escrita somente talvez não conseguisse penetrar. Ao compreenderem que a história de Javé é a história de cada um, os alunos se reconheceram sujeitos, protagonistas de suas próprias histórias e da História. Os relatos a seguir evidenciam essa questão:

"Eu aprendi muito mais a conhecer não só a História, mas
também a mim mesma. Pensar que também faço História";
"É outro jeito de aprender História: sair do texto. Aprendemos
assim, além de nossas expectativas"; "Eu achava que as
aulas este ano iam ser iguais aos outros anos: só texto
maçante, copiado do livro, questões para responder, um
monte de coisa chata que eu não sei prá que aquilo. Esse
ano foi tudo diferente. As aulas de História foram mais legais,
animadas, mexeram com a criatividade, com a imaginação".

2 Estado localizado no sul do Brasil onde ocorreram desmoronamentos e inundações provocados por fortes chuvas, vitimando inúmeras pessoas 


\section{Considerações finais}

As complexas implicações subjetivas existentes entre os fatos históricos e as histórias individuais evidenciaram-se nesta pesquisa, assim como as relações entre o recurso das memórias dos alunos e suas produções de sentidos na aula de História. De fato, construir conhecimento histórico pode ser mais fácil quando o professor considera que o aluno produz sentidos sobre suas próprias criações e sobre as relações que mantém com o outro com quem convive e com o meio histórico-cultural no qual está inserido.

A utilização do filme como recurso na aula de História revelou-se um grande facilitador para a conversação, para o resgate da memória - individual e coletiva - e para a compreensão dos sentidos subjetivos que os alunos produziam nos processos de aprendizagem da História. Isto evidenciou a importância da utilização de metodologias diferenciadas a serem utilizadas como recursos pedagógicos, sobretudo nas aulas de História, que propiciam um movimento de reflexão e de ação muito apropriado para o processo de aprendizagem e de produção de sentidos anunciado por Placco e Souza (2006, p. 25)

O recurso da memória na aula de História, ao refazer e recriar as experiências passadas entrelaçadas à dimensão subjetiva do sujeito pode ser explicitado e enriquecido não só com o auxílio de palavras, mas também de imagens, de ideias, etc., recursos que trazem a marca do movimento, do inacabado, da dimensão processual em direção ao futuro provocando transformações e permanências.

O enredo do filme fez com que os alunos produzissem sentidos perceptivos em seus relatos e se conscientizassem da importância de cada um ao fazer história. Eles se mostraram e se compreenderam como parte do processo histórico. Houve um entrelaçamento entre suas trajetórias de vida, suas memórias e a aprendizagem da História.

Desse modo, também se percebeu nesta pesquisa que a aula de História não pode reduzir-se a um espaço meramente reprodutor de fatos históricos ou ficar aquém das possibilidade de reflexão. Isto não significa restringir a aula de História à dimensão prazerosa e espontânea, nem compreendê-la a partir de uma abordagem relativista, mas considerá-la em sua dimensão de complexidade, assim como o sujeito e os processos de aprender e de ensinar.

Desse modo, compreendeu-se com mais clareza que os processos de ensinar e aprender História não se dissociam e que podem ser facilitados quando a revelação de aspectos da subjetividade dos alunos são favorecidos em sala de aula e compreendidos como algo em permanente construção, em uma dimensão de complexidade.

Este estudo procurou investigar e apresentar alguns recursos facilitadores para a aprendizagem de História e tornou-se convite à reflexão sobre as possibilidades de abertura de caminhos e a busca de alternativas que apontem para a melhoria da qualidade das aulas de História nas escolas.

\section{Referências}

Gatti, B. (2003). Formação continuada de professores: a questão psicossocial. Cadernos de Pesquisa, 119, 191-204.

González Rey, F. (2003). Sujeito e Subjetividade. São Paulo: Editora Pioneira Thomson.

González Rey, F. (2005). Pesquisa qualitativa e subjetividade: os processos de construção da informação. São Paulo: Editora Pioneira Thomson.

González Rey, F. (2012). A configuração subjetiva dos processos psíquicos: avançando na compreensão da aprendizagem como produção subjetiva. Em A. Martínez, B. J. L. Scoz, \& Castanho, M. I. S. (Orgs.), Ensino e aprendizagem: a subjetividade em foco (pp. 21-41). Brasília: Editora Líber livros.

Halbwachs, M. (2004). A memória coletiva. São Paulo: Editora Centauro.

Morin, E. (1997). Método 1: a natureza da natureza. Sintra: Publicações Europa-América.

Placco, V. M. N.S., \& Silva, S. H. S. (2000). A formação do professor: reflexões, desafios e perspectivas. Em E. B. G. Bruno, L. R. Almeida, \& L. H. S. Christov (Orgs.), O coordenador pedagógico e a formação docente (pp. 25-32). São Paulo: Editora Loyola.

Placco, V. M. N. S., \& Souza, V. L. T. (2006). Aprendizagem do adulto professor. São Paulo: Editora Loyola.

Scoz, B. J., Castanho, M. I. S., \& Tacca C. V. R. (2010). Ensino e Aprendizagem: contribuições das pesquisas a partir da perspectiva da subjetividade. Relatório técnico científico de pesquisa. Brasília: CNPq.

Scoz, B. J. L., Castanho, M. I. S., \& Tacca C. V. R. (2012). Subjetividade, ensino e aprendizagem: contribuições das pesquisas acadêmicas. Em A. M. Martinez, B. J. L. Scoz, \& M. I. S. Castanho (Orgs), Ensino e aprendizagem: a subjetividade em foco (pp. 131-155). Brasília. Editora Líber Livros.

Scoz, B. J., Castanho, M. I. S., \& Tacca C. V. R. (2010). Ensino e Aprendizagem: contribuições das pesquisas a partir da perspectiva da subjetividade. Relatório técnico científico de pesquisa. Brasília: CNPq. 


\section{Sobre as autoras}

Beatriz Judith Lima Scoz (beatrizscoz@uol.com.br)

Doutorado e Mestrado pela Pontifícia Universidade Católica de São Paulo - PUC/SP, Pós-doutorado pela Universidade Federal de Brasília - UnB

Vilma Nardes Silva Rodrigues (vnardes@bol.com.br)

Mestre pelo Centro Universitário FIEO/UNIFIEO - SP 